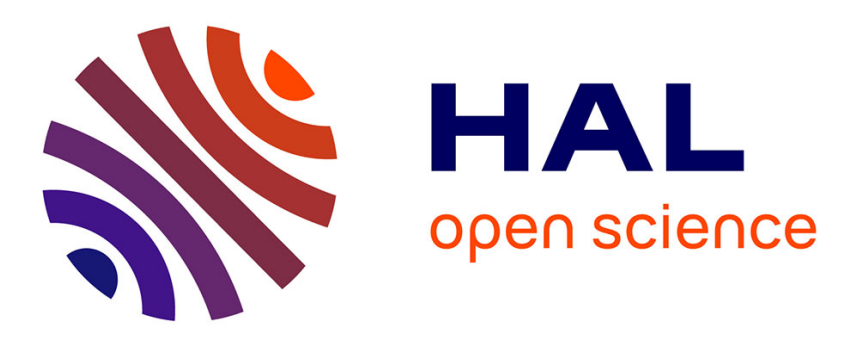

\title{
Uncertainty assessment of concrete electrical resistivity measurements on a coastal bridge.
}

Lucas Bourreau, Véronique Bouteiller, Franck Schoefs, Laurent Gaillet, Benoit Thauvin, Julien Schneider, Samuel Naar

\section{- To cite this version:}

Lucas Bourreau, Véronique Bouteiller, Franck Schoefs, Laurent Gaillet, Benoit Thauvin, et al.. Uncertainty assessment of concrete electrical resistivity measurements on a coastal bridge.. Structure and Infrastructure Engineering, 2019, 15 (4), pp. 443-453. 10.1080/15732479.2018.1557703 . hal03258681

\section{HAL Id: hal-03258681 \\ https://hal.science/hal-03258681}

Submitted on 11 Jun 2021

HAL is a multi-disciplinary open access archive for the deposit and dissemination of scientific research documents, whether they are published or not. The documents may come from teaching and research institutions in France or abroad, or from public or private research centers.
L'archive ouverte pluridisciplinaire HAL, est destinée au dépôt et à la diffusion de documents scientifiques de niveau recherche, publiés ou non, émanant des établissements d'enseignement et de recherche français ou étrangers, des laboratoires publics ou privés. 


\title{
Uncertainty assessment of concrete electrical resistivity measurements on a coastal bridge.
}

\author{
Lucas Bourreau a, Véronique Bouteiller b , Franck Schoefs ${ }^{\text {c,* }}$, Laurent Gaillet ${ }^{\text {d, }}$ \\ Benoît Thauvin ${ }^{\text {e }}$, Julien Schneider ${ }^{\text {f }}$, Samuel Naar ${ }^{\mathrm{g}}$
}

${ }^{a}$ SIXENSE Concrete, Siège Social, F78350 Jouy-en-Josas, France

${ }^{\mathrm{b}}$ Université Paris-Est, MAST, SDOA, IFSTTAR, F-77447 Marne-la-Vallée, France

c Université Bretagne Loire, Université de Nantes, Centrale Nantes, UMR CNRS 6183, Research Institute in Civil Engineering and Mechanics, France, IUML FR CNRS 3473, Sea and Littoral research Institute, Nantes, France

${ }^{\text {d }}$ Université Bretagne Loire, IFSTTAR, MAST, SMC, F44344 Bouguenais, France

${ }^{\mathrm{e}}$ Cerema Ouest, F22015 Saint-Brieuc, France

${ }^{\mathrm{f}}$ Cerema Ile-de-France, F77171 Sourdun, France

g SIXENSE Concrete, Agence Ouest, F44115 Haute-Goulaine, France

* Corresponding author. E-mail address: franck.schoefs@univ-nantes.fr; Tel.: +33 251125522

\begin{abstract}
During the diagnosis of existing structures, errors can be generated by uncertainty of measurements. The latter are affected by several factors and should be evaluated on-site. In this paper, a large data of resistivity values (1800 measurements) measured on a bridge
\end{abstract}


in a marine environment has been gathered utilizing a four electrodes probe under specific procedures. The uncertainty assessment based on measurements repeatability or local material anisotropy and variability were characterized from this database. Moreover, considering the uncertainty results together with the corrosion risk from RILEM TC154 recommendation, Probability of Wrong Assessment (PWA) is evaluated. Finally, the influence of uncertainty and PWA were discussed in order to help the owner of the bridge in taking decision on additional measurements or complementary investigations.

Keywords: Resistivity Measurements; Reinforced concrete; Marine environment; Uncertainty of measurements; Probabilistic modelling; Probability of corrosion; Diagnosis.

\section{Introduction}

In Europe, most civil engineering reinforced concrete (RC) structures were built during the last 60 years and their ageing is becoming a great challenge in terms of deterioration assessment, repair decision and management strategy (Woodward et al., 2001; Tilly \& Jacobs, 2007; Bastidas \& Schoefs, 2015). Corrosion, which is recognised as the main cause of RC deterioration, can occur when the concrete cover is completely carbonated or when chloride ions have penetrated up to the rebar level (Broomfield, 1997; Bentur et al., 1997; Bertolini et al., 2004). Within the European cooperation in the field of scientific and technical research, reports on the corrosion and protection of reinforcement in concrete have been published (Cox et al., 1997; Cigna et al., 2003, COST TU 1404). 
Moreover, dealing with chloride-induced corrosion, some results can be found in (Montemor et al., 3003; Poupard et al., 2006; Poupard et al., 2007).

For RC structures exposed to marine environments, chloride-induced corrosion leads to deteriorations that can be associated to different exposure conditions: tidal, splash and atmospheric. On-site, assessment of corrosion condition of reinforcement in concrete is based on a corrosion diagnosis which relies on the results of several techniques (Cox et al., 1997; Reichling et al., 2013; Raupach et al., 2013; Nanukuttan et al., 2013; Sanchez et al., 2017). Among them, Non Destructive Techniques (NDT) such as half-cell potential (Elsener, 2003), resistivity (Polder, 2000; Polder, 2001) and corrosion measurements (Andrade \& Alonso, 2004) are increasingly used.

In addition, on-site measurements include environmental factors and on-site material variability taht induce variability and uncertainties in NDT condition assessment. The latter need a better understanding and a modeling in order to measure its impact on the diagnosis and increase the reliability of the diagnosis (Breysse et al., 2009; Breysse \& Abraham, 2005). This phenomenon is enhanced for marine structures and only few papers are available in comparison with structures in atmospheric environment.

The objectives of the Project DéCoF-Ré ${ }^{1}$ (2014-2017) were to study both the concrete durability and the corrosion state of the piers of the Ile de Ré bridge which is located in the French Atlantic coast. Concerning the corrosion study, visual inspections, rebar localization, half-cell potential mapping (Bourreau et al., 2016), electrical concrete resistivity mapping and corrosion rate measurements were performed during three years in order to analyse the influence of the measurement procedures, the investigated zones (pier number, side, height) and the environments (tide level, climatic conditions).

\footnotetext{
${ }^{1}$ Décision Corrosion Fiabilité - Pont de l'Ile de Ré
} 
This paper focuses on the resistivity measurements conducted with a four electrodes arrangement probe (Wenner type) on the piers of the Ile de Ré bridge using a floating platform on a boat. Resistivity measurements qualify the electrical resistivity of the concrete cover and not the resistivity of the steel/concrete interface, which is usually obtained by Linear Polarisation Resistance measurements. Although this NDT tool cannot directly provide information on the passive/active state of the rebar (Hornbostel et al., 2013), it is a useful NDT to point out the areas where the corrosion might be strongest: that gives a first assessment of the probability of corrosion. The purpose of this paper is to outline the errors made while measuring the resistivity from an uncertainty assessment based on both (i) the measurement uncertainty evaluated from repeatability tests and (ii) the local material anisotropy. Moreover, a model based on the evaluation of Probability of Wrong Assessment of the probability of corrosion is proposed to help the owner of the bridge in taking a decision on additional measurements or complementary investigations.

\section{Material and methods of resistivity measurements}

\subsection{Presentation of the Ile de Ré bridge}

The Ile de Ré bridge (Figure 1), located in the French Atlantic coast, was built in 19871988 to provide an access to the Ré island from La Rochelle mainland. The bridge has a total length of 2928.5 meters, a width of 15 meters and a maximum height above the sea level of 30 meters (navigation channel). The bridge deck was constructed on 28 piers, from which 24 piers were founded in the sea (Figure 2). Environmental conditions around the bridge are as follow: main wind directions are North/North West, average monthly salinity of water results of the mixture of sea water and water from 3 rivers and varies

annually in the range $31 \mathrm{~g} / \mathrm{l}$ (winter) and $35 \mathrm{~g} / \mathrm{l}$ (summer), average monthly air 
temperature varies from $8^{\circ} \mathrm{C}$ (winter) to $22^{\circ} \mathrm{C}$ (summer), average monthly water temperature is in the range $11^{\circ} \mathrm{C}$ (winter) to $21^{\circ} \mathrm{C}$ (summer) and the maximum tide range is $6.7 \mathrm{~m}$.

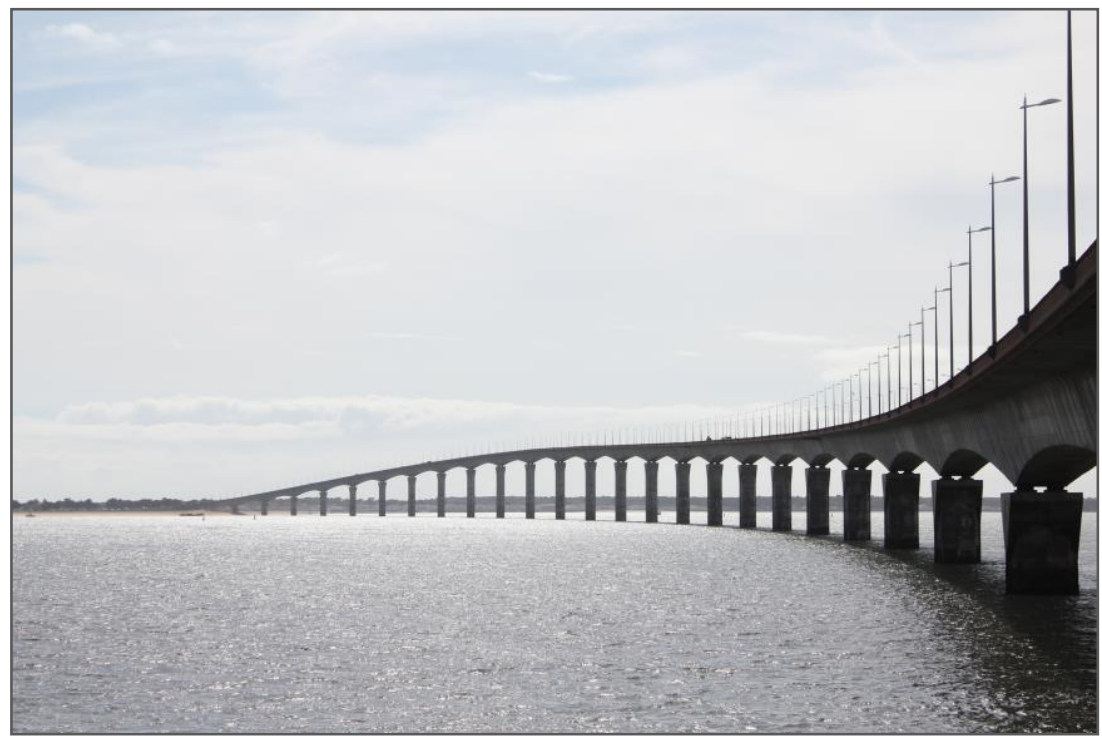

Figure 1: Ile de Ré bridge (@ V. Bouteiller, IFSTTAR).

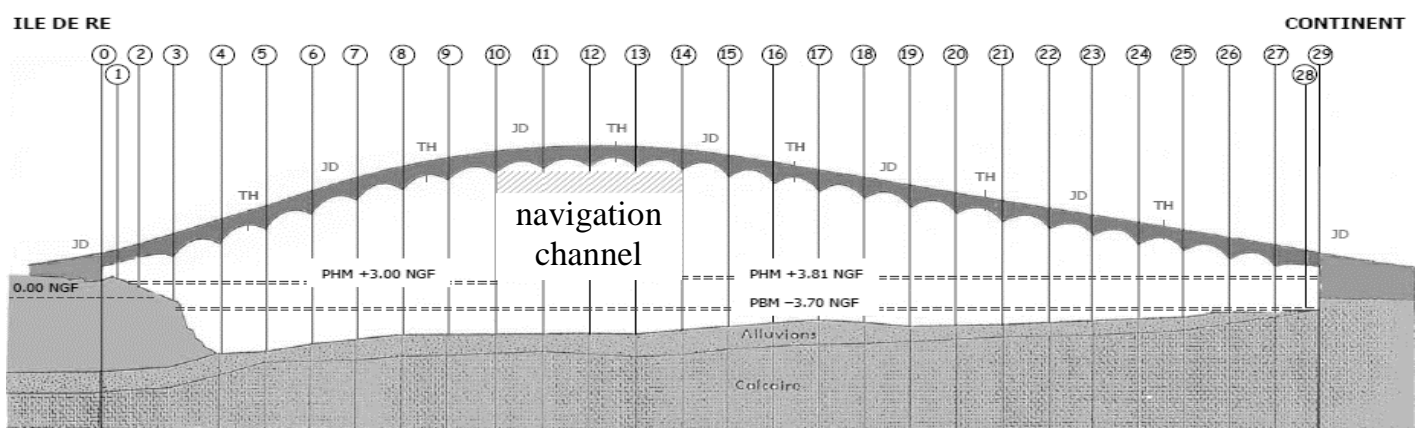

Figure 2: Ile de Ré bridge - longitudinal scheme.

\subsection{Concrete resistivity measurements using a four electrode probe}

The resistivity measurements were performed from a floating platform using a Proceq RESIPOD $^{\circledR}$ probe, which follows the Wenner technique (Polder, 2000; Polder 2001; 
Hornbostel et al., 2013; Wenner, 1915; Gowers \& Millard, 1999). This probe is composed of four equally spaced electrodes, which ensure the electrical contact with the concrete surface. As illustrated in Figure 3, a small alternative current I is injected between the outermost electrodes trough the concrete cover and the resultant potential difference $\mathrm{V}$ is measured between the two inner electrodes. The concrete electrical resistivity $\rho$ for a semi-infinite geometry is given by (1), where "a" is the electrode spacing (5cm for the Resipod probe). In the case of measurements performed on samples in laboratory, the error of measurements coming from the device itself, as given by the constructor is $\xi_{\boldsymbol{\rho}, \mathrm{dev}}=3 * \boldsymbol{\sigma}_{\boldsymbol{\rho}, \mathrm{dev}}=2.4 \mathrm{k} \Omega . \mathrm{cm}$.

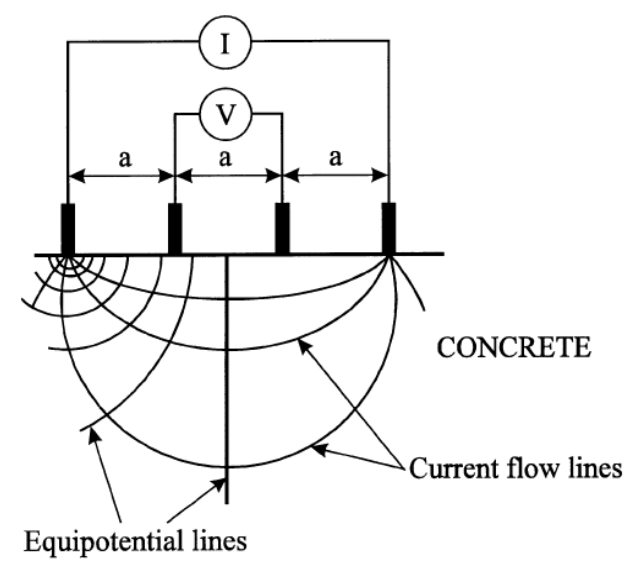

Figure 3: Four electrodes probe for measuring concrete resistivity (Gowers \& Millard, 1999).

$$
\rho=2 \pi * \mathrm{a} * \frac{V}{I}
$$




\subsection{Resistivity measurements on the piers of the Ile de Ré bridge}

Corrosion diagnosis was performed during 3 years on 15 piers (14 offshore and 1 onshore) from visual inspections, rebar localization, half-cell potential mapping, electrical concrete resistivity mapping and corrosion rate measurements. Measurements were carried out on two opposite sides of the piers as illustrated in Figure 4: side C was more exposed to dominant winds and daily sunshine leading to a stronger action of wetting/drying cycles whereas side $G$ was less exposed. The dimensions of the investigated zones were $3 \mathrm{~m}$ height and $1.85 \mathrm{~m}$ width. Measurements were carried out between $+3.95 \mathrm{~m}$ and $+6.95 \mathrm{~m}$ Chart Datum $(\mathrm{CD})$. Chart Datum fixes an absolute sea level reference along the French coast and in this paper, La Rochelle - La Pallice harbour was considered as the reference. As the objective of the paper was to assess and to model uncertainty of resistivity measurements, the influence of the corrosion was disregarded, considering a pier, which was, diagnosed passive on both sides. The diagnosis relied first on the absence of pathologies due to corrosion from visual inspection and second on the absence of anodic area from half-cell potential measurements (Bourreau et al., 2018).

Measurements were performed during the rising tide, thus allowing the concrete to dry and to oxygenate during about 2-3 hours for the bottom part (1m high) and about 6-7 hours for the higher part (2-3 meters): concrete is gradually exposed to wind and sun during falling tide and before it is wetted by rising tide. Measurements started from the bottom going upward (Y increased). The investigated meshes (dimensions approximately $30 \times 20 \mathrm{~cm})$ were between 2 vertical reinforcing bars (V4 $(X=0.66 \mathrm{~m})$ and V5 (X=0.96 m)) as indicated in Figure 5 far enough from the edges of the pier, which therefore had no effect on the measurements. For this pier, side C consisted of 13 meshes and side G 15 . 
Note that horizontal reinforcements were not positioned at the same height and we plot on Figure 5 the exact position of the meshes obtained from radar pre-measurements.

In terms of measurement area now, it is well known that the metal conducts the current better than the concrete and therefore a disturbance of the current flow could have been observed, if electrodes were located too close to the rebars (Weydert \& Gehlen, 1999). Thus, it was decided to carry out measurements in a smaller area whose limits were $5 \mathrm{~cm}$ distance from the rebars (see Figure 6). According to this criterion, one mesh of side $\mathrm{C}$ and three of side $\mathrm{G}$ were too small to perform the tests. Thus 12 measurement windows inside the remaining meshes were useful for each side. The center of the window was obtained with the diagonals in view to ensure a good precision of repeatability tests. Prior to measurements, the window was wetted during one minute with fresh water. The measurements in a window did not last more than two minutes and during this time the humidity remained constant. Table 1 presents the temperature and the relative humidity during the measurements, provided by the weather station in the floating platform.

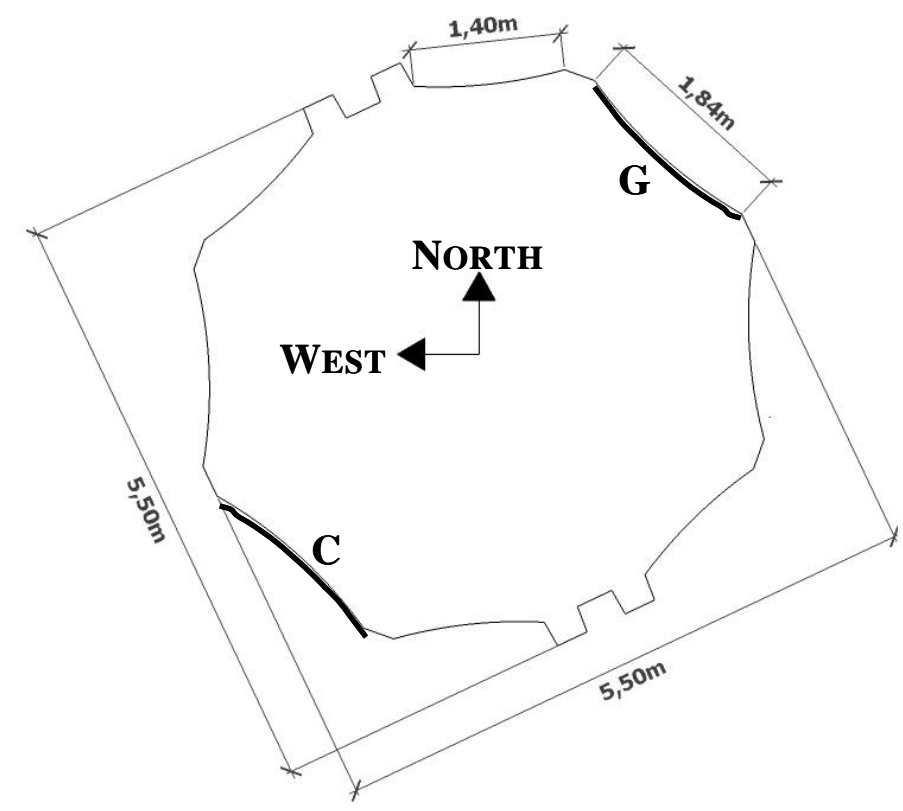

Figure 4: Top view of the pier and exposure sides $C$ and $G$. 

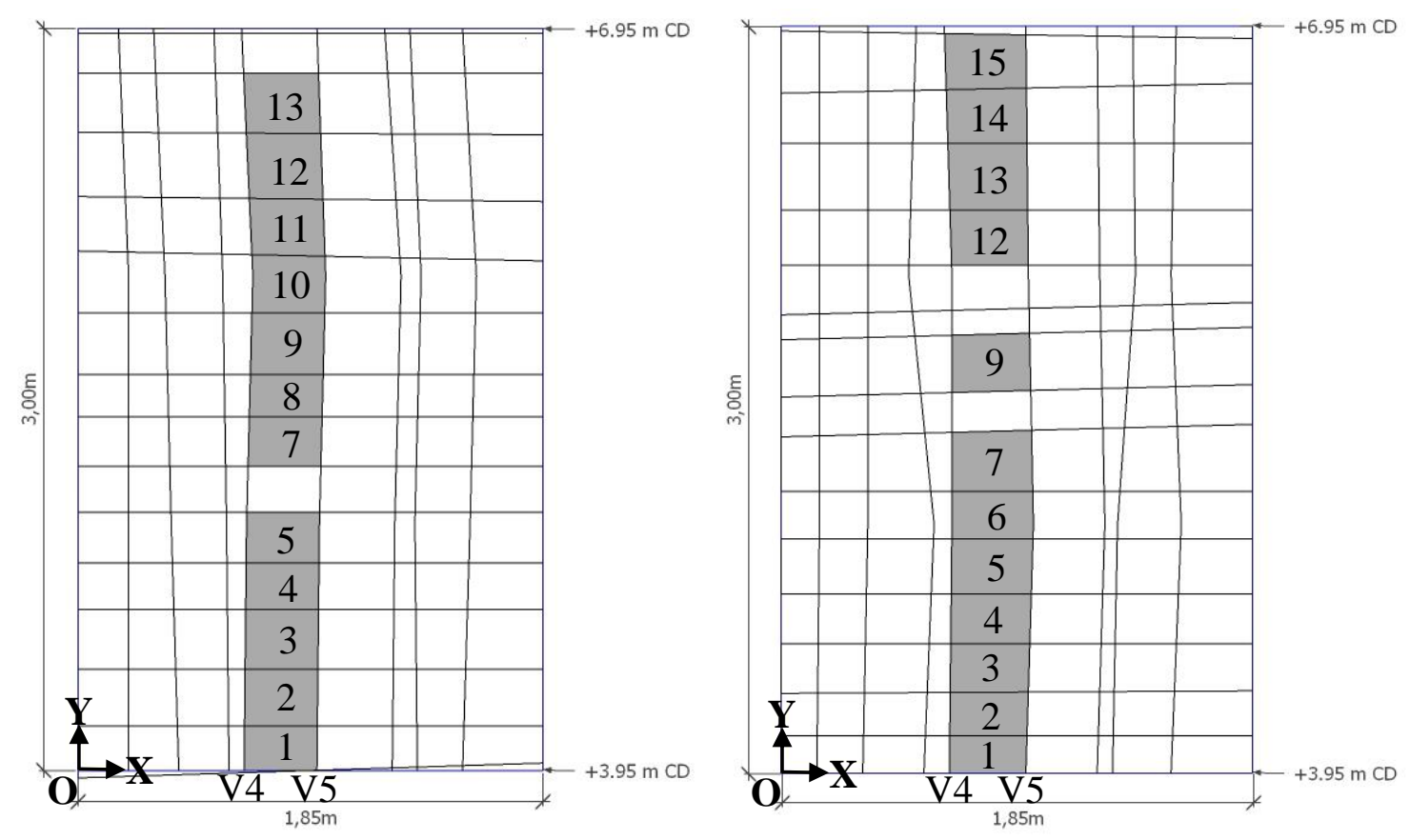

Figure 5: Position of the steel rebars and of the meshes for sides $C$ (left) and G (right).
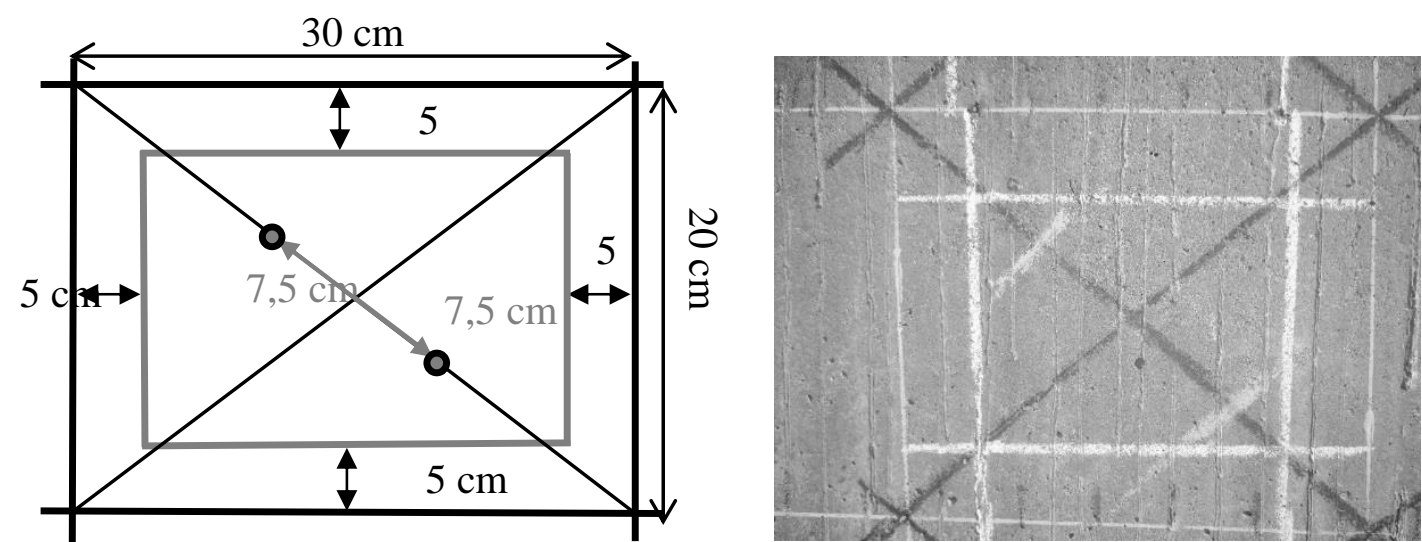

Figure 6: Measurement window inside the mesh bounded by rebars: scheme (left) and on site (right).

Table 1: Temperature and relative humidity during the measurements.

\begin{tabular}{|c|c|c|}
\hline & Temperature $\left({ }^{\circ} \mathrm{C}\right)$ & Relative Humidity (\%) \\
\hline Maximum & 21.4 & 63.5 \\
\hline Minimum & 15.7 & 45.9 \\
\hline Mean & 18.5 & 54.7 \\
\hline
\end{tabular}




\subsubsection{Procedure for the repeatability test}

The objective was to determine the repeatability of the resistivity measurements when performed on-site. For this purpose, the probe was always positioned according to direction II (Figure 7) and 35 consecutive measurements on the same location were carried out in each mesh. The 12 windows of sides $\mathrm{C}$ and $\mathrm{G}$ were investigated, leading to a total of 420 measurements for each pier.

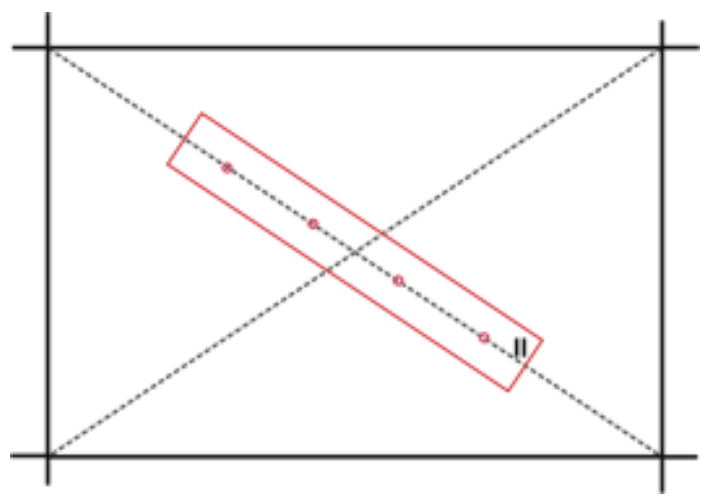

Figure 7: Measurement window and position of the probe according to direction II for repeatability measurements.

\subsubsection{Procedure for evaluating local material anisotropy and measurements variability}

The objective was to determine the material variability's effect on the concrete resistivity measurements and its dependence to concrete fabrication, in the same measurement window. Laying concrete induces two directions of anisotropy: vertical and horizontal. Vibration of concrete lowers this anisotropy on the one hand by randomizing concrete and enhances it on the other hand due to the geometry of concrete vibrators and the human factor. In fact, on-site vibration is a complex step: vibrator should be vertical, penetrate into the previous layer and be withdrawn slowly. Quality of vibration results in 
homogenization but is hard to achieve. The electrode being a one directional tool, the vertical layering resulting from laying and the horizontal in-homogeneity resulting from vibration could affect the measurement depending on the orientation of the probe, especially vertical and horizontal ones, even if the apparent volume of material under consideration was the same. The objective is herein to measure the effect of this local anisotropy.

The duration of measurements being limited during a tide, the objective is to cover a wide range of situations with a limited number of measurements. To reach this objective, the experimental procedure was built considering 4 orientations of the probe (denoted I to IV on Figure 8-left): the measure was repeated 10 times for each orientation by covering the whole available surface as shown for direction I on Figure 8 right. A total of 960 measurements were performed: 4 orientations, 2 sides, 12 meshes, 10 times. This original protocol allows analysing and quantifying the effect of the vertical or horizontal gradient due to a potential segregation by the concreting.
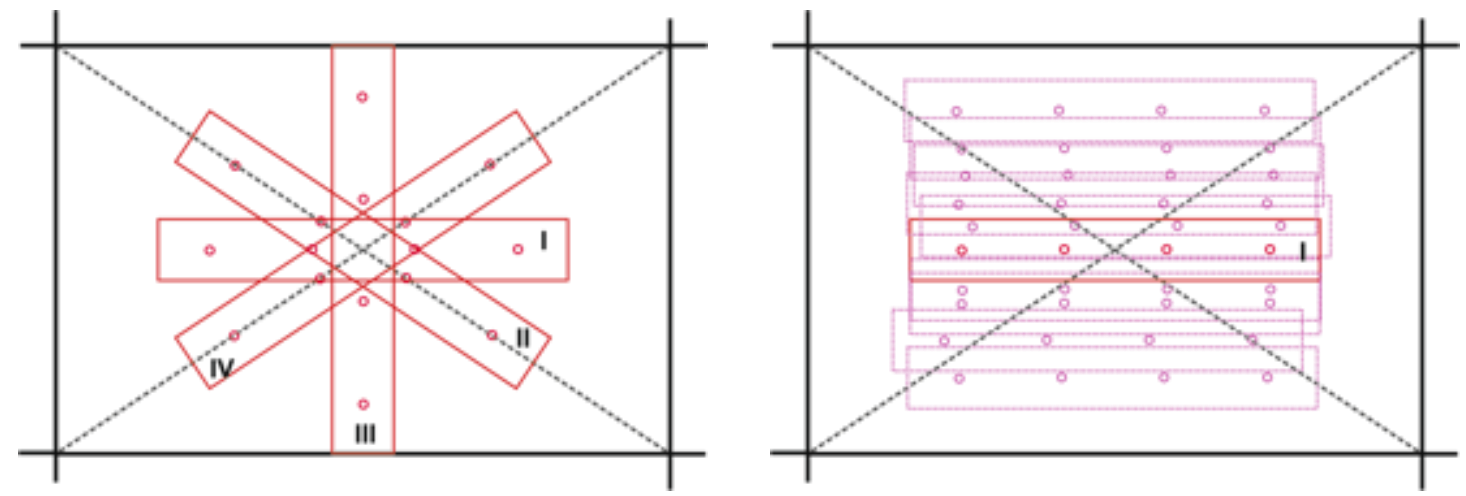

Figure 8: Scheme of the measurement window and positions (I, II, III and IV (clockwise)) of the probe (left) and 10 measurements according to direction I (right). 


\section{Statistical analysis of repeatability and local anisotropy tests}

In order to perform statistical analyses of the local material anisotropy (index 'mat' in the following) and repeatability studies (index 'rep' in the following), an assumption has to be stated. Assuming that on-site measurements were affected by no bias and that errors were centred, the mean value of repeatability measurements was considered as the true value (Schoefs et al., 2009; Boéro et al., 2012).

\subsection{Analysis of repeatability test for resistivity measurements}

The repeatability tests were performed according to the procedure described in $§ 2.3 .1$. The mean value $\mu_{\boldsymbol{\rho}, \text { rep }}$ and the standard deviation $\sigma_{\boldsymbol{\rho}, \text { rep }}$ were computed for each measurement window. Figure (a) plots for each of the 12 measurement windows of side C, the 35 resistivity values and the corresponding average resistivity. Similarly, Figure 9 (b) plots the results of the 35 measurements for the 12 measurement windows of side $\mathrm{G}$. For both exposures (sides $\mathrm{C}$ and $\mathrm{G}$ ), results showed that for resistivity measurements in the range $10-160 \mathrm{k} \Omega . \mathrm{cm}$, the scatter increases with the mean resistivity $(10-150 \mathrm{k} \Omega . \mathrm{cm}$ range). To quantify this trend, the evolution of the standard deviation with the mean resistivity is presented in Figure 10.

All the values were fitted with a linear relation (Erreur! Source du renvoi introuvable.) which regression coefficient was equal to 0.96. Linear fitting parameters were 0.13 for the slope, leading to a constant coefficient of variation of $13 \%$, and near zero for the $y$-intercept $(-2,05 \mathrm{k} \Omega . \mathrm{cm})$. The latter was in the same range of magnitude of the standard deviation of the device error measured in laboratory of $0.8 \mathrm{k} \Omega . \mathrm{cm}$ (device error: $+/-2.4 \mathrm{k} \Omega . \mathrm{cm}$ ) indicating that the assumption of the zero-bias was acceptable. The standard deviation is neglected (equal to 0 ) for $\mu_{\boldsymbol{\rho}, \text { rep }}<15.5 \mathrm{k} \Omega . \mathrm{cm}$. Therefore, it was 
found that when performing resistivity measurements on-site, the scattering of the measurements increases by a factor of about 20 in comparison with laboratory: standard deviation reaches $17 \mathrm{k} \Omega . \mathrm{cm}$ on site. To our knowledge, this result was not shown until now including in review papers where errors of measurement are generally not discussed (Azarsa \& Gupta, 2017):

- $\quad$ it was shown that on site measurements in presence of rebar were affected by large errors (Sanchez et al., 2017);

- repeatability tests were carried out only in laboratory leading to lower uncertainties (Balayssac et al., 2012);

- global uncertainties were assessed on site (Polder, 2000) without distinguishing the effect of the protocol itself through repeatability tests.

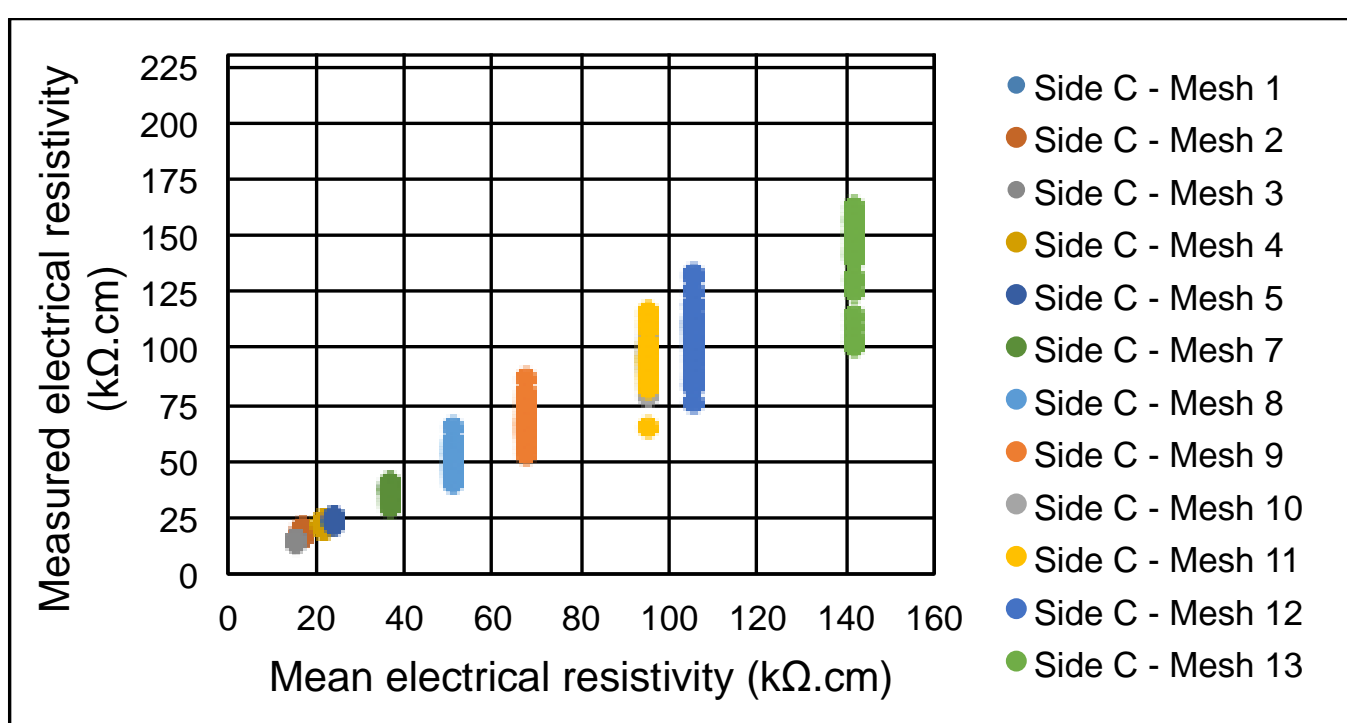




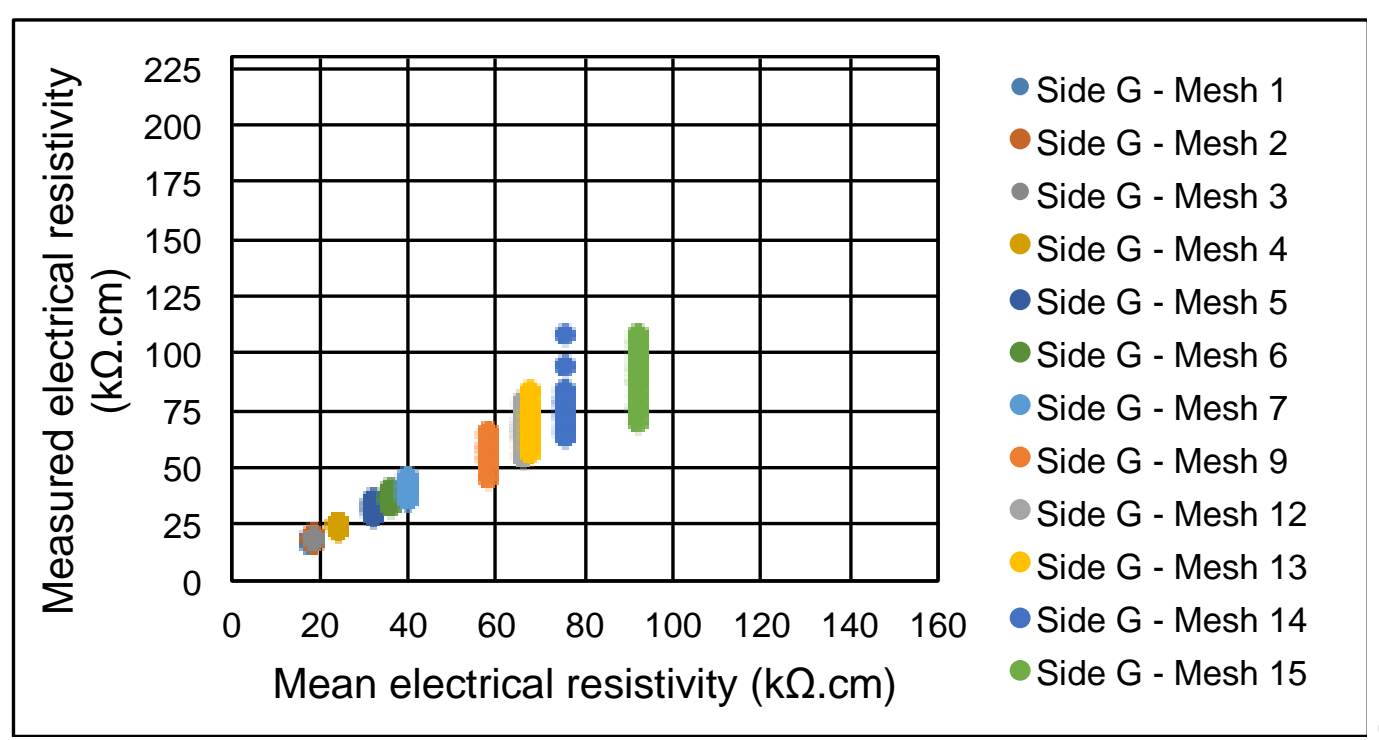

Figure 9: Scatter of the repeatability test for side $C(a)$ and side $G(b)$.

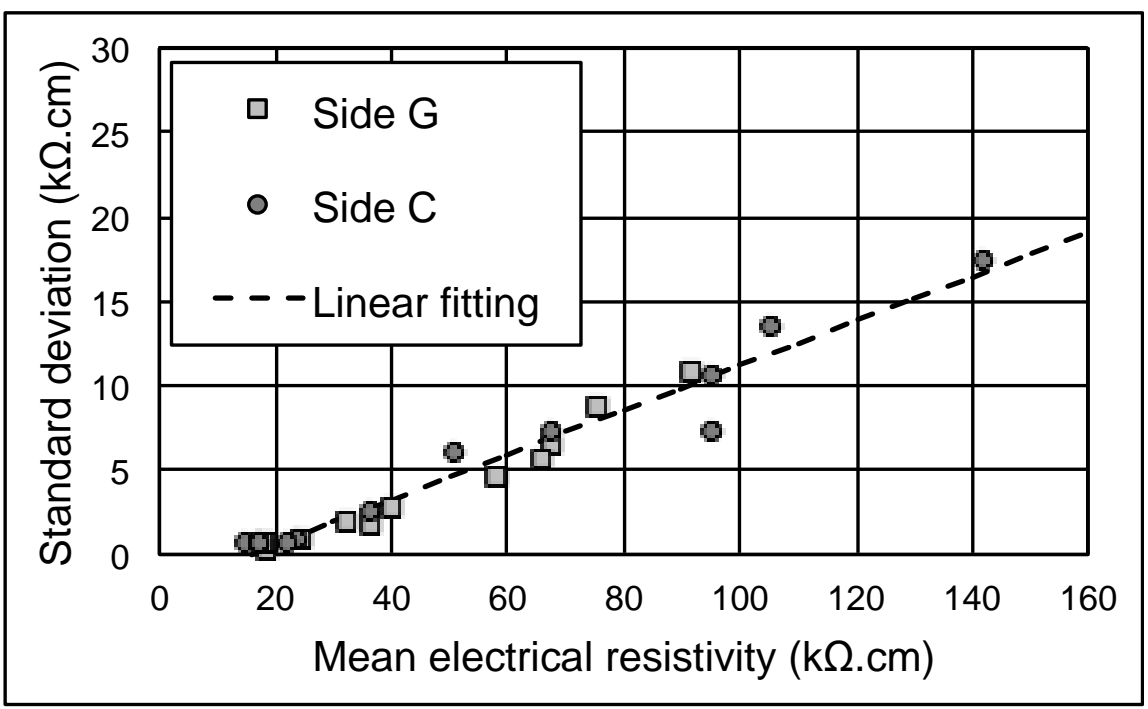

(c

Figure 10: Evolution of standard deviation with mean resistivity for the repeatability test.

$$
\begin{gathered}
\sigma_{\boldsymbol{\rho}, \text { rep }}=0.1324 \mu_{\boldsymbol{\rho}, \text { rep }}-2.05 \text { for } \mu_{\boldsymbol{\rho}, \text { rep }} \geq 15.5 \mathrm{k} \Omega . \mathrm{cm} \\
\sigma_{\boldsymbol{\rho}, \text { rep }}=0 \text { for } \mu_{\boldsymbol{\rho}, \text { rep }}<15.5 \mathrm{k} \Omega . \mathrm{cm}
\end{gathered}
$$




\subsection{Joint influence of the local material anisotropy and the repeatability on the resistivity assessment}

The joint effect of local material anisotropy and repeatability were determined from measurements according to the procedure described in $\S 2.3 .2$. As both effects cannot be measured separately, the variability of measurements was labelled as total uncertainty (tot). The mean value $\mu_{\boldsymbol{\rho}, \text { tot }}$ and the standard deviation $\sigma_{\boldsymbol{\rho}, \text { tot }}$ were computed for each mesh. For side $\mathrm{C}$ and for each mesh, Figure 11 (a) plots the 40 resistivity (4 orientations $\mathrm{x} 10$ times) values measured on one mesh versus its mean value inside the mesh. Similarly, Figure 11 (b) presents the results for side $G$, where the scattering is similar to that of side $\mathrm{C}$ for similar mean resistivity (for instance 60 or $90 \mathrm{k} \Omega . \mathrm{cm}$ ). There is no effect of the side of exposure directly but indirectly through the range of mean electrical resistivity. It was reported on Figure 12 the evolution of the standard deviation according to the mean electrical resistivity. It was found that the scattering of the resistivity measurements was not increasing with the mean resistivity following a linear but an exponential relationship, showing a non-constant coefficient of variation. After mean square regression (with large regression coefficient $\mathrm{R}^{2}=0.96$ ), the same equation (3) was obtained whatever the sides and the ranges of resistivity, showing an intrinsic evolution of the scatter with the mean resistivity. This equation is plotted in dashed line on Figure 12.

Equation (3) covers a mean resistivity range from 10 to $140 \mathrm{k} \Omega . \mathrm{cm}$. For a $140 \mathrm{k} \Omega . \mathrm{cm}$ mean resistivity value, an error of $30 \%$ was found. This is in good agreement with the RILEM recommendation where a coefficient of variation of $30 \%$ was considered as normal for on-site measurements (Polder, 2000). 


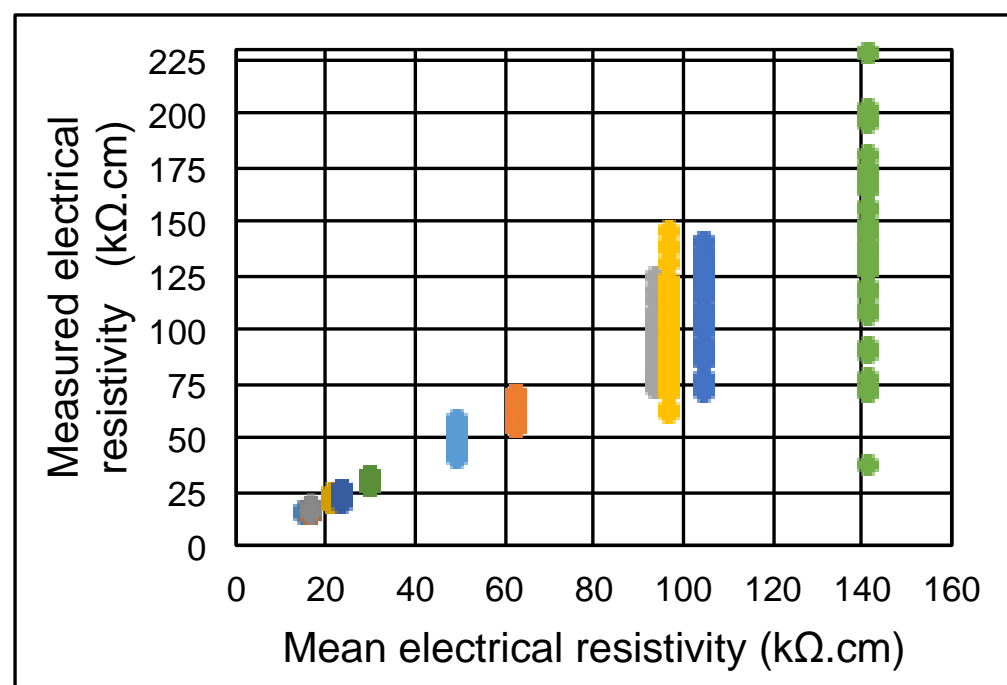

- Side C - Mesh 1

- Side C - Mesh 2

- Side C - Mesh 3

- Side C - Mesh 4

- Side C - Mesh 5

- Side C - Mesh 7

- Side C - Mesh 8

- Side C - Mesh 9

- Side C - Mesh 10

- Side C - Mesh 11

- Side C - Mesh 12

- Side C - Mesh 13

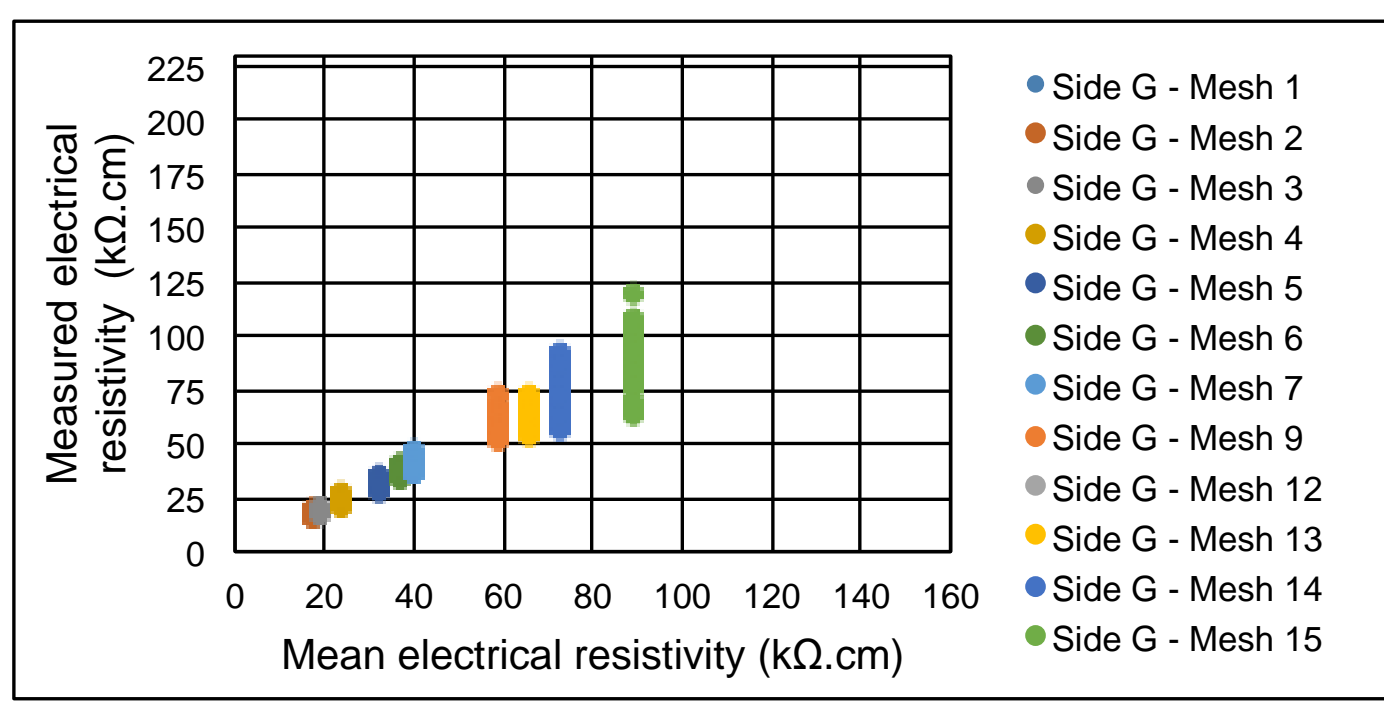

Figure 11: Scatter of the measured resistivity inside a mesh versus the mean resistivity considering local material anisotropy and measurements variability, for side $C(a)$ and side $G(b)$. 


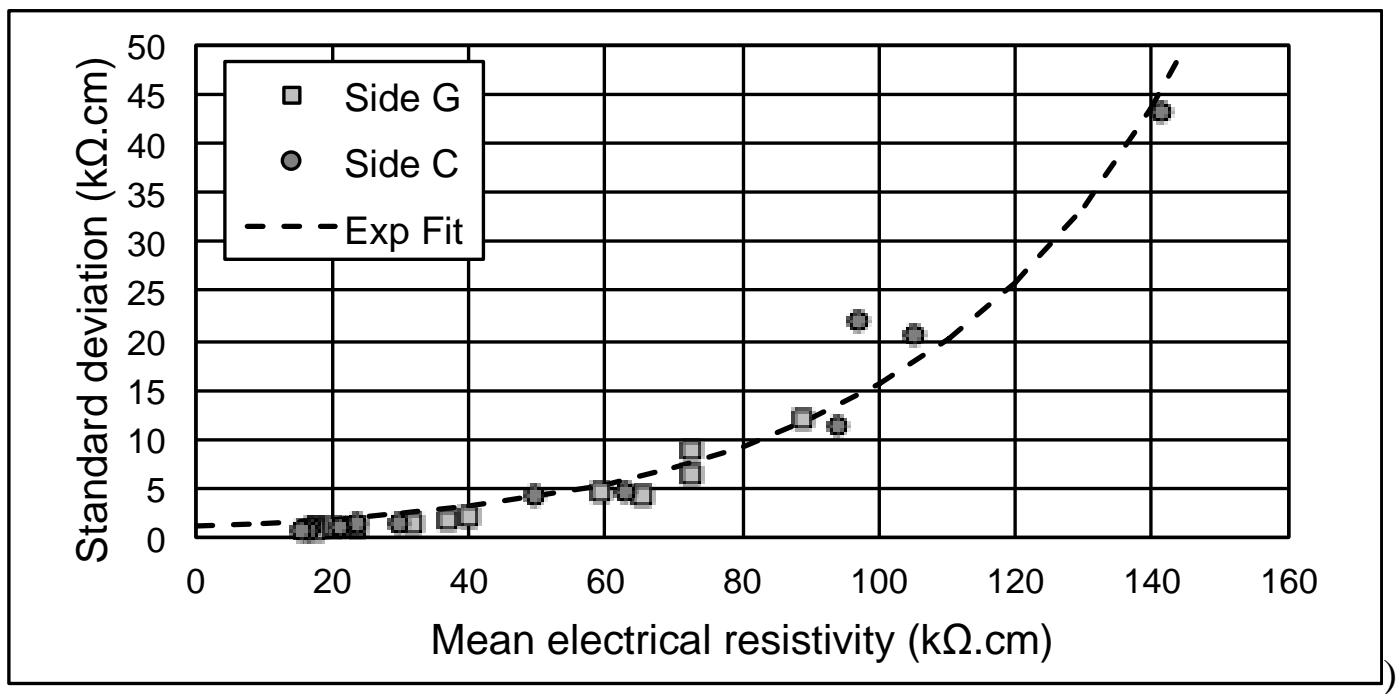

Figure 12: Evolution of standard deviation with mean resistivity for local anisotropy and measurement variability's.

$$
\sigma_{\boldsymbol{\rho}, t o t}=1.16 e^{0.026 \cdot \mu_{\boldsymbol{\rho}, t o t}}
$$

\section{Modelling resistivity uncertainty and its effect on diagnosis}

In this section, the first objective is to discuss the statistical modelling of the uncertainty of resistivity measurements performed on-site by distinguishing the effect of material variability and protocol uncertainty. The second objective is to evaluate how this uncertainty can influence the decision concerning the corrosion probability, using a probabilistic approach.

\subsection{Modelling material variability and repeatability uncertainties of resistivity measurements}

Uncertainties coming from the material variability and the repeatability test are generated by separate sources: one is inherent to the measurement and the other to the material anisotropy. That is the reason why these two uncertainties are usually modelled as independent random variables (Schoefs et al., 2009). The total uncertainty of resistivity 
measurements is thus modelled as the addition of the uncertainties coming from the material variability (mat) and the repeatability test (rep). The probabilistic writing is the summation of random variable in Eq. 4.

$$
\varepsilon_{\rho, \operatorname{tot} \mid \mu \rho}=\varepsilon_{\rho, \text { mat } \mid \mu \rho}+\varepsilon_{\rho, \operatorname{rep} \mid \mu \rho}
$$

Where $\mu_{\boldsymbol{\rho}}$ denotes the mean value of resistivity in the measurement window, assumed to be the true value $\rho$.

Standard deviation of total error of measurement $\sigma_{\boldsymbol{\rho}, \text { tot }}$ can, then, be written according to $(5)$.

$$
\sigma_{\boldsymbol{\rho}, \operatorname{tot} \mid \mu \rho}=\sqrt{\sigma_{\boldsymbol{\rho}, \operatorname{mat} \mid \mu \rho}^{2}+\sigma_{\boldsymbol{\rho}, \operatorname{rep} \mid \mu \rho}^{2}}
$$

Where $\sigma_{\boldsymbol{\rho} \text {,mat }}$ is the standard deviation of the local material anisotropy and $\sigma_{\boldsymbol{\rho} \text {,rep }}$ is the standard deviation of the repeatability uncertainty already computed in section 3.1.

After evaluation of $\sigma_{\boldsymbol{\rho}, \text { tot }}, \sigma_{\boldsymbol{\rho}, \text { rep }}$ from measurements and knowing $\mu_{\boldsymbol{\rho}}, \sigma_{\boldsymbol{\rho}, \text { mat }}$ can be computed from Eq. 5. Let us analyse if $\mu_{\mathbf{p}}$ was dependent on the protocol in each measurement window, i.e. the local anisotropy and the repeatability protocols. Figure 13 plost $\mu_{\boldsymbol{\rho}, \text { rep versus }} \mu_{\boldsymbol{\rho} \text {,tot }}$ for each of the 24 meshes. It shows a very good agreement with a mean error between these quantities of $4 \%$. We assume in the following that: $\mu_{\mathbf{\rho}, \mathbf{r e p}}=\mu_{\mathbf{\rho}, \text { tot }}$ $=\mu_{\boldsymbol{\rho}}$ according to a usual assumption for the determination of the true value (Schoefs et al., 2009). This assumption allows computing directly of $\sigma_{\boldsymbol{\rho} \text {,mat }}$ by using (2) and (3). 


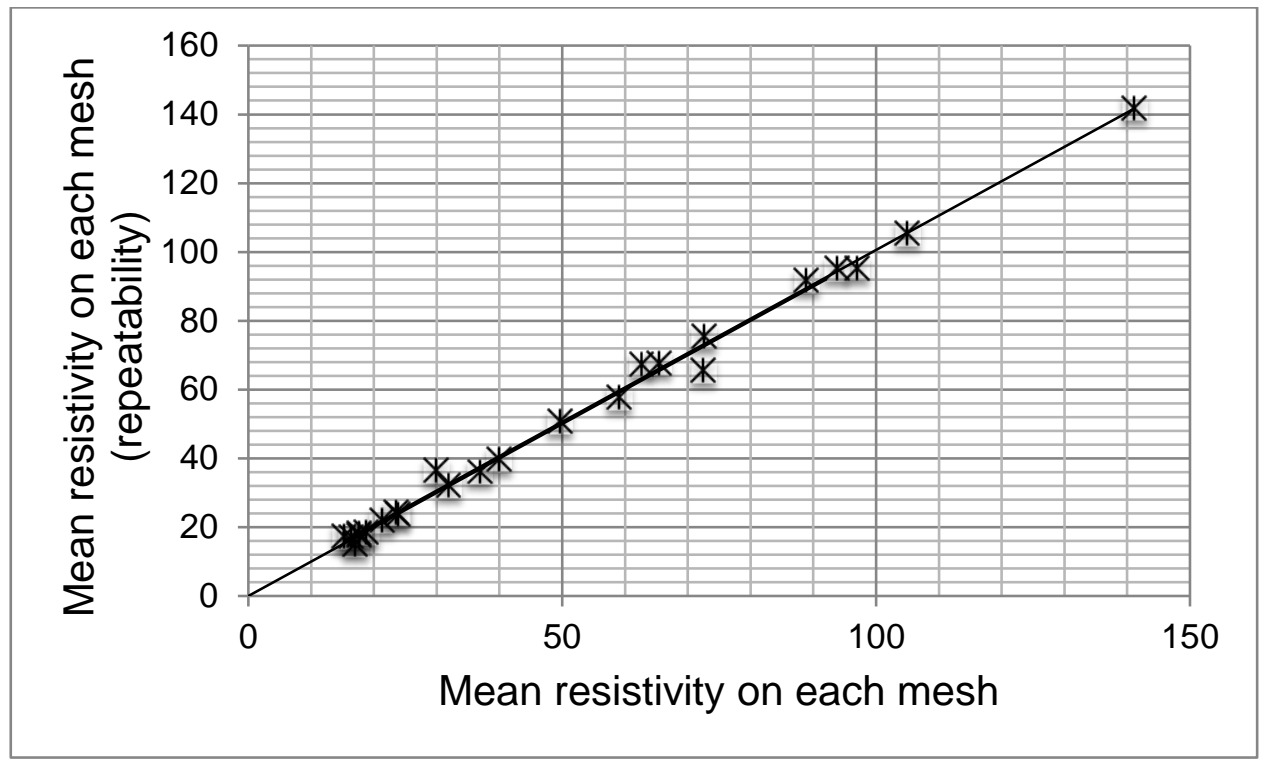

Figure 13: Scatter diagram of $\mu_{\rho, \text { rep }}$ according to $\mu_{\rho, t o t}$

Figure 14 presents the evolution of the analytical expressions of each standard deviation with $\mu_{\boldsymbol{\rho}}$. In this figure, as determined in section 3 from equations (2) and (3), the standard deviation from the total (local material anisotropy and measurements variability's) and from the repeatability tests are plotted. Moreover, the evolution of the calculated standard deviation of the material (Erreur ! Source du renvoi introuvable.) is represented in dashed line. Finally, the lower boundary $(0.8 \mathrm{k} \Omega . \mathrm{cm})$ indicated in red represents the standard deviation of $\sigma_{\rho, d e v}$, the standard deviation of the uncertainty of the error of the device itself. In the case where the fitting of $\sigma_{\rho, \text { rep }}$ gives $\sigma_{\rho, \text { rep }}<\sigma_{\rho, \text { dev }}$, it has been assumed that $\sigma_{\rho, r e p}=\sigma_{\rho, d e v .}$. From these results it was found that the expression of the material variability follows an exponential relation (6).

$$
\left\{\begin{array}{c}
\sigma_{\boldsymbol{\rho}, \text { mat }}^{2}=\sigma_{\boldsymbol{\rho}, \text { tot }}^{2}-\sigma_{\boldsymbol{\rho}, \text { rep }}^{2}=1.35 e^{0.052 . \mu_{\boldsymbol{\rho}}}-\left(0.1324 \mu_{\boldsymbol{\rho}}-2.05\right)^{2} \\
\text { for } \mu_{\boldsymbol{\rho}, \text { rep }} \geq 15.5 \mathrm{k} \Omega . \mathrm{cm} \\
\sigma_{\boldsymbol{\rho}, \text { mat }}^{2}=1.35 e^{0.052 . \mu_{\boldsymbol{\rho}}} \text { for } \mu_{\boldsymbol{\rho}, \text { rep }}<15.5 \mathrm{k} \Omega . \mathrm{cm}
\end{array}\right.
$$

Where $\mu_{\boldsymbol{\rho}}$ denotes the mean value on the measurement window. 
These results also highlight that for resistivity values higher than $95 \mathrm{k} \Omega . \mathrm{cm}$, the local material anisotropy plays the dominant role whereas for values lower than $95 \mathrm{k} \Omega . \mathrm{cm}$ it is the repeatability. To complete the findings of this paper and in order to provide a general modelling of the concrete resistivity obtained on-site, a broader range of resistivity including parameters such as different concrete formulations/contaminations and different exposure conditions should be studied.

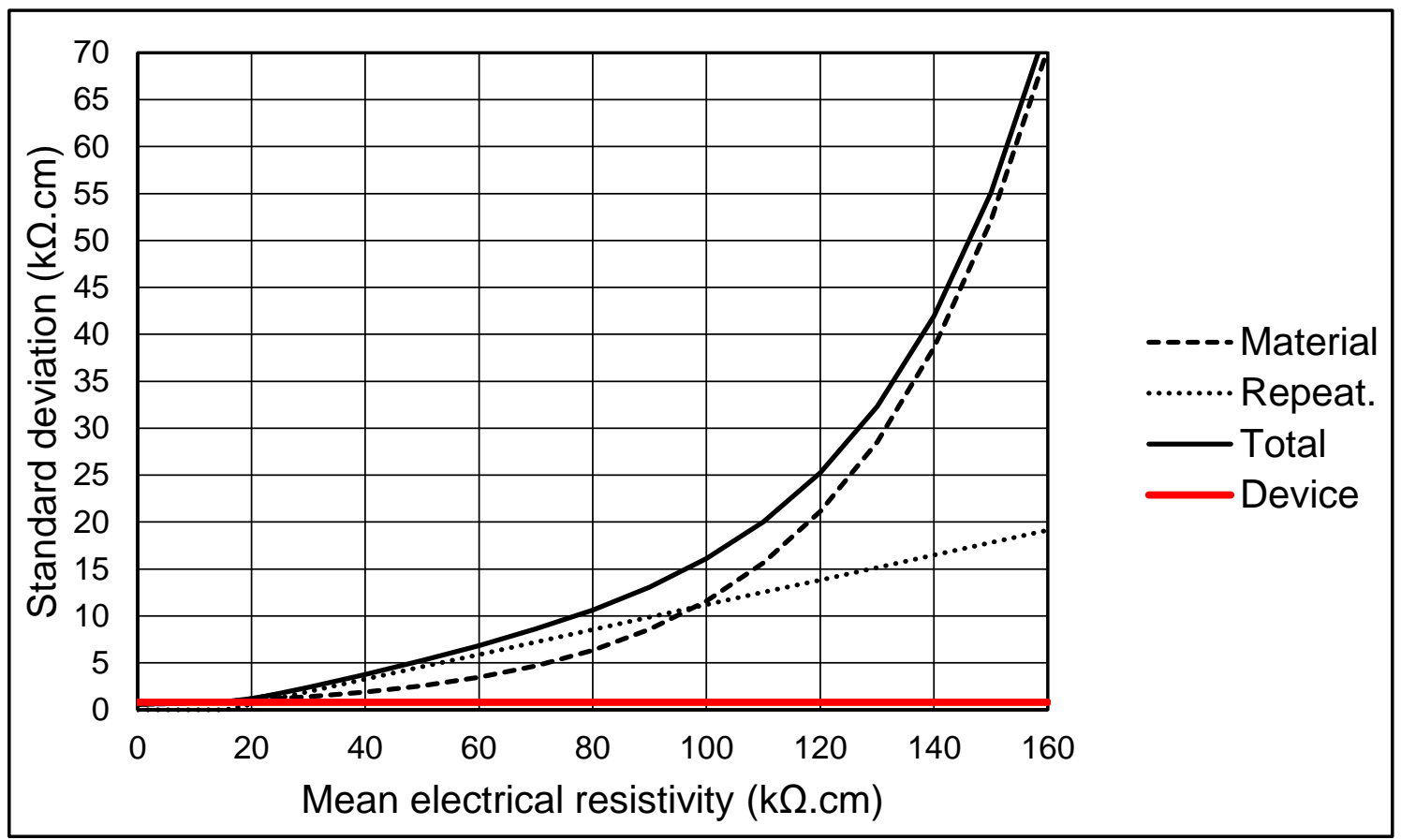

Figure 14: Evolution of the standard deviations of total, repeatability and material errors with mean concrete resistivity.

\subsection{Uncertainty assessment of concrete resistance measurements and consequence on corrosion probability assessment}

In this section, considering the previous results and the levels of corrosion associated with the resistivity ranges given by the RILEM (Polder, 2000) (Table 2), we propose a 
probabilistic approach to check when uncertainties lead to over- or under-estimate the corrosion probability.

The non-destructive technique of concrete electrical resistivity has become increasingly popular to assess the corrosion probability of RC structures because, first, the measurements are quite easy to perform (in the laboratory and on site) and second, the RILEM TC154 (Polder, 2000) published a recommendation where concrete resistivity ranges were associated to four risks of reinforcement corrosion (Table 2). It is important to note that these corrosion risks were determined for Ordinary Portland Cement (OPC) under laboratory conditions $\left(20^{\circ} \mathrm{C}\right)$. Moreover, in the same recommendation, the RILEM TC154 [15] also presented some reference data derived from various laboratory studies, considering resistivity measurements performed for different cement types and exposures, at $20^{\circ} \mathrm{C}($ Table 3$)$.

Table 2: Risk of corrosion of the reinforcement for OPC concretes associated with resistivity values $\left(20^{\circ} \mathrm{C}\right)$.

\begin{tabular}{c|c}
\hline $\begin{array}{c}\text { Concrete resistivity } \\
\rho_{\text {concrete }}(\mathrm{k} \Omega . \mathrm{cm})\end{array}$ & Risk of corrosion \\
\hline$<10$ & High $(\mathrm{H})$ \\
$10-50$ & Moderate $(\mathrm{M})$ \\
$50-100$ & Low (L) \\
$>100$ & Negligible (N) \\
\hline
\end{tabular}


Table 3: General values at $20^{\circ} \mathrm{C}$ for the electrical resistivity of dense-aggregate concrete of existing structures (age >10 years); conditions under brackets are comparable to laboratory conditions.

\begin{tabular}{|c|c|c|}
\hline \multirow[b]{2}{*}{ Environment } & \multicolumn{2}{|c|}{ Concrete resistivity $\rho_{\text {concrete }}(\mathrm{k} \Omega . \mathrm{cm})$} \\
\hline & $\begin{array}{l}\text { Ordinary Portland } \\
\text { cement (CEM I) }\end{array}$ & $\begin{array}{l}\text { Blast furnace slag cement } \\
(>65 \% \text { slag, CEM III/B) or } \\
\text { fly ash }(>25 \%) \text { cement or } \\
\text { silica fume }(>5 \%) \text { concretes }\end{array}$ \\
\hline $\begin{array}{l}\text { Very wet, submerged, } \\
\text { splash zone, [fog room] }\end{array}$ & $5-20$ & $30-100$ \\
\hline Outside, exposed & $10-40$ & $50-200$ \\
\hline $\begin{array}{l}\text { Outside, sheltered, } \\
\text { coated, hydrophobised (not } \\
\text { carbonated) }\left[20^{\circ} \mathrm{C} / 80 \% \mathrm{RH}\right]\end{array}$ & $20-50$ & $100-400$ \\
\hline Ditto, carbonated & 100 and higher & 200-600 and higher \\
\hline $\begin{array}{l}\text { Indoor climate } \\
\text { (carbonated) } \\
{\left[20^{\circ} \mathrm{C} / 50 \% \mathrm{RH}\right]}\end{array}$ & 300 and higher & 400-1000 and higher \\
\hline
\end{tabular}

Probabilistic modeling provides the theoretical framework for defining and assessing false decisions. Considering the uncertainty of the resistivity measurements $\varepsilon_{t o t}$, the total error of measurement can lead to a false decision on corrosion probability of rebars (7): over- or under-estimation of the corrosion probability. 


$$
\hat{\rho}=\rho+\varepsilon_{t o t \mid \rho}
$$

Where $\hat{\rho}$ denotes the measured value, $\rho$ the true value and $\varepsilon_{\text {tot } \mid \rho}$ the total error when assessing $\rho$.

From a probabilistic point of view, probability of good assessment of the corrosion probability is usually defined as probability of good (PGA) or wrong (PWA) assessment (Pasqualini et al., 2013). Considering the four electrodes probe device, the detection threshold $a_{\rho}$ is taken at $2.4 \mathrm{k} \Omega . \mathrm{cm}$, which is three times the standard deviation of the device error. Considering the corrosion riks levels of the RILEM, the thresholds are defined as $\rho_{H M}=10 \mathrm{k} \Omega . \mathrm{cm}, \rho_{M L}=50 \mathrm{k} \Omega . \mathrm{cm}$ and $\rho_{L N}=100 \mathrm{k} \Omega . \mathrm{cm}$. Then, the probability of wrong assessment (PWA) of each risk assessment considering an over-estimation is calculated according to equations (8), (9) and (10) when skipping one level of corrosion probability; equations (11) and (12) refer to the probability to skip two levels of corrosion probability; (13) refers to the probability to skip three levels. The relations for calculating the probability of wrong assessment considering an over-estimation are written below:

Prob. of Low probability of corrosion assessment instead of Negligible

$$
\mathrm{PWA}_{\mathrm{NL}}=\mathrm{P}\left(\rho_{M L} \leq \hat{\rho} \leq \rho_{L N} \mid \rho \geq \rho_{L N} \& \rho \geq a_{\rho}\right)
$$

Prob. of Moderate probability of corrosion assessment instead of Low

$$
\mathrm{PWA}_{L M}=\mathrm{P}\left(\rho_{H M} \leq \hat{\rho} \leq \rho_{M L} \mid \rho_{L N} \geq \rho \geq \rho_{M L} \& \rho \geq a_{\rho}\right)
$$

Prob. of High probability of corrosion assessment instead of Moderate 


$$
\mathrm{PWA}_{M H}=\mathrm{P}\left(\hat{\rho} \leq \rho_{H M} \mid \rho_{M L} \geq \rho \geq \rho_{H M} \& \rho \geq a_{\rho}\right)
$$

Prob. of Moderate probability of corrosion assessment instead of

Negligible

$$
\mathrm{PWA}_{\mathrm{NM}}=\mathrm{P}\left(\rho_{H M} \leq \hat{\rho} \leq \rho_{M L} \mid \rho \geq \rho_{L N} \& \rho \geq a_{\rho}\right)
$$

Prob. of High probability of corrosion assessment instead of Low

$$
\mathrm{PWA}_{\mathrm{LH}}=\mathrm{P}\left(\hat{\rho} \leq \rho_{H M} \mid \rho_{L N} \geq \rho \geq \rho_{M L} \& \rho \geq a_{\rho}\right)
$$

Prob. of High probability of corrosion assessment instead of Negligible

$$
\mathrm{PWA}_{\mathrm{NM}}=\mathrm{P}\left(\hat{\rho} \leq \rho_{H M} \mid \rho \geq \rho_{L N} \& \rho \geq a_{\rho}\right)
$$

Figure 15 presents the evolution according to the concrete electrical resistivity of the non-negligible probabilities that will lead to an over-estimation. The probability (PWA $\mathrm{PH}_{\mathrm{NH}}$ of skipping three levels of corrosion probability was less than $0.1 \%$. The probabilities (PWA PM $_{\mathrm{NM}}$ and PWA $\mathrm{LH}_{\mathrm{LH}}$ ) for skipping two levels of corrosion probability were negligible (less than 1\%). This means that the threshold values from the RILEM are different enough to avoid an error of assessment by skipping two or more levels of corrosion probability. Considering the over-estimation based on one level of corrosion probability, the PWA reaches a significant value only when concrete resistivity's were close to the thresholds. The fact that PWANL exceeds $25 \%$ from 80 to $100 \mathrm{k} \Omega . \mathrm{cm}$ can be explained by to the non-linear evolution of the standard deviation of the measurement error in Figure 14. 


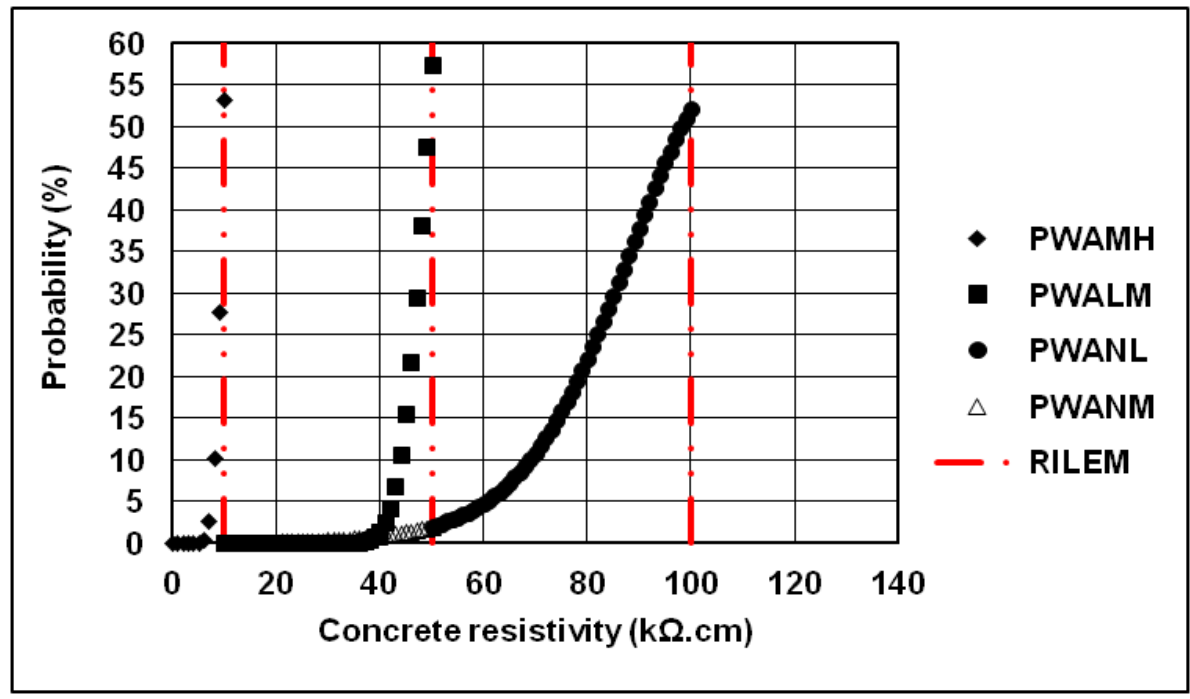

Figure 15: Probability of wrong assessment leading to over-estimation of the corrosion probability.

On the other hand, when considering under-estimation, the probability of wrong assessment can be calculated according to equations (14), (15) and (16).

Prob. of Negligible probability of corrosion assessment instead of Low

$$
\mathrm{PWA}_{\mathrm{LN}}=\mathrm{P}\left(\rho_{L N} \leq \hat{\rho} \mid \rho_{L N} \geq \rho \geq \rho_{M L} \& \rho \geq a_{\rho}\right)
$$

Prob. of Low probability of corrosion assessment instead of Moderate

$$
\mathrm{PWA}_{M L}=\mathrm{P}\left(\rho_{M L} \leq \hat{\rho} \leq \rho_{L N} \mid \rho_{M L} \geq \hat{\rho} \geq \rho_{H M} \& \rho \geq a_{\rho}\right)
$$

Prob. of Moderate probability of corrosion assessment instead of High

$$
\mathrm{PWA}_{H M}=\mathrm{P}\left(\rho_{H M} \leq \hat{\rho} \leq \rho_{M L} \mid \rho_{H M} \geq \rho \& \rho \geq a_{\rho}\right)
$$




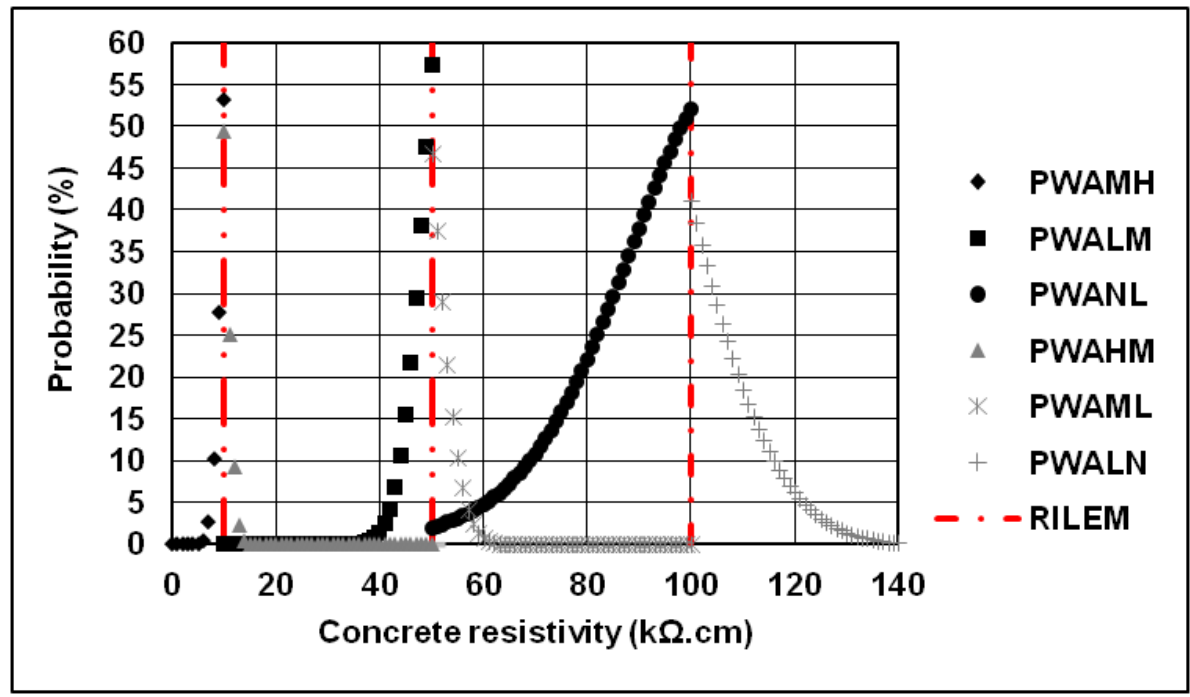

Figure 16: Probability of wrong assessment leading to an over- or under-estimation of the corrosion probability.

Figure 16 presents the non-negligible probabilities of wrong assessment considering both over- and under-estimation. For a $25 \%$ PWA, the ranges of concrete resistivity with higher PWA were found as: 8-12 k $\Omega . c m, 43-57 \mathrm{k} \Omega . \mathrm{cm}$ and $82-107 \mathrm{k} \Omega . \mathrm{cm}$. The higher the measured value the higher the range: this comes from the exponential evolution of error of measurement. The conclusion is that for higher values of resistivity, the error of assessment is higher but as the corrosion probability decreases when concrete resistivity increases, the diagnosis on the corrosion probability will not be significantly wrong. Therefore, the probability of error of assessment of high corrosion probability is significantly lower than assessment of moderate probability.

Finally, from these results and considering the whole resistivity measurements performed on both sides of the pier on the Ile de Ré bridge, iso-curves of resistivity and their corresponding iso-curves of PWA are gathered in Table 4. Due to the non-linear 
evolution of error of assessment with average resistivity, resistivity and PWA maps are not similar in some locations where measured values are near the thresholds (bottom left on side $\mathrm{C}$ and middle on side G). The PWA plot could therefore highlight the locations where the error of corrosion probability assessment between two levels is important. For side $\mathrm{C}$ that is the case bottom left where the iso-curves show no gradient but where some values are close to a bound and lead to high probability of wrong assessment. For side G, in the middle, iso-curves show significant gradients and for some values they are close to bounds leading to high probability of wrong assessment. Note that for both sides $\mathrm{C}$ ad G, high values of resistivity ( $>100 \mathrm{k} \Omega . \mathrm{cm}$ ) are located at the top: from Figure 14 we can conclude that anisotropy can be detected only in that area.

Table 4: Iso-curves of PWA for selected $C$ and $G$ sides.

\begin{tabular}{|c|c|c|c|c|}
\hline & Iso-curves of resistivity & $\begin{array}{l}\text { Legend } \\
(\mathrm{k} \Omega . \mathrm{cm})\end{array}$ & Iso-curves of PWA & $\begin{array}{c}\text { Legend } \\
(\%)\end{array}$ \\
\hline Side & 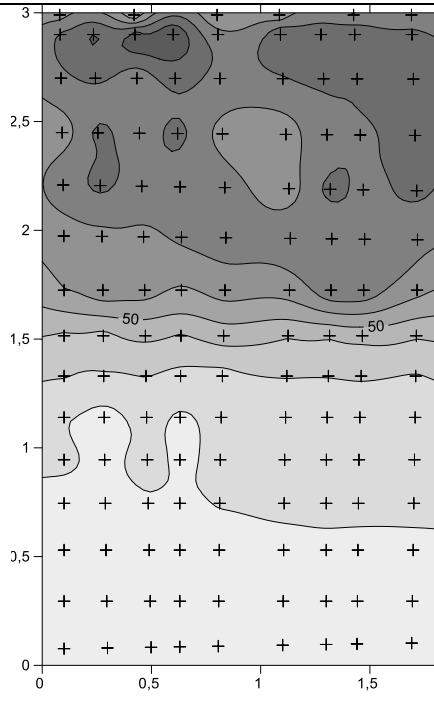 & $\begin{array}{l}140 \\
130 \\
120 \\
110 \\
100 \\
90 \\
80 \\
70 \\
60 \\
50 \\
40 \\
30 \\
20 \\
10 \\
0\end{array}$ & 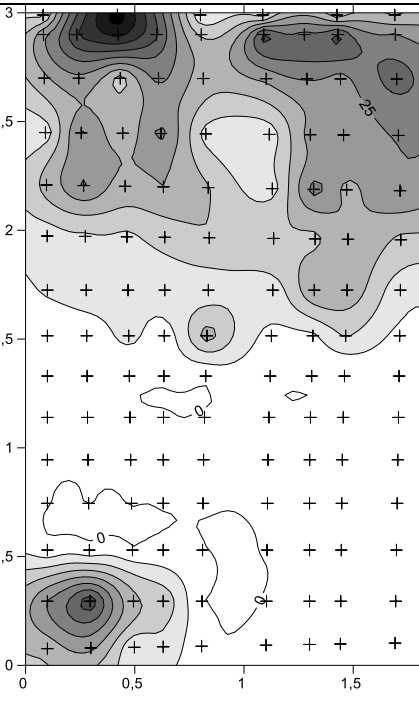 & $\begin{array}{l}25 \\
20 \\
15 \\
10 \\
5 \\
\\
\end{array}$ \\
\hline
\end{tabular}




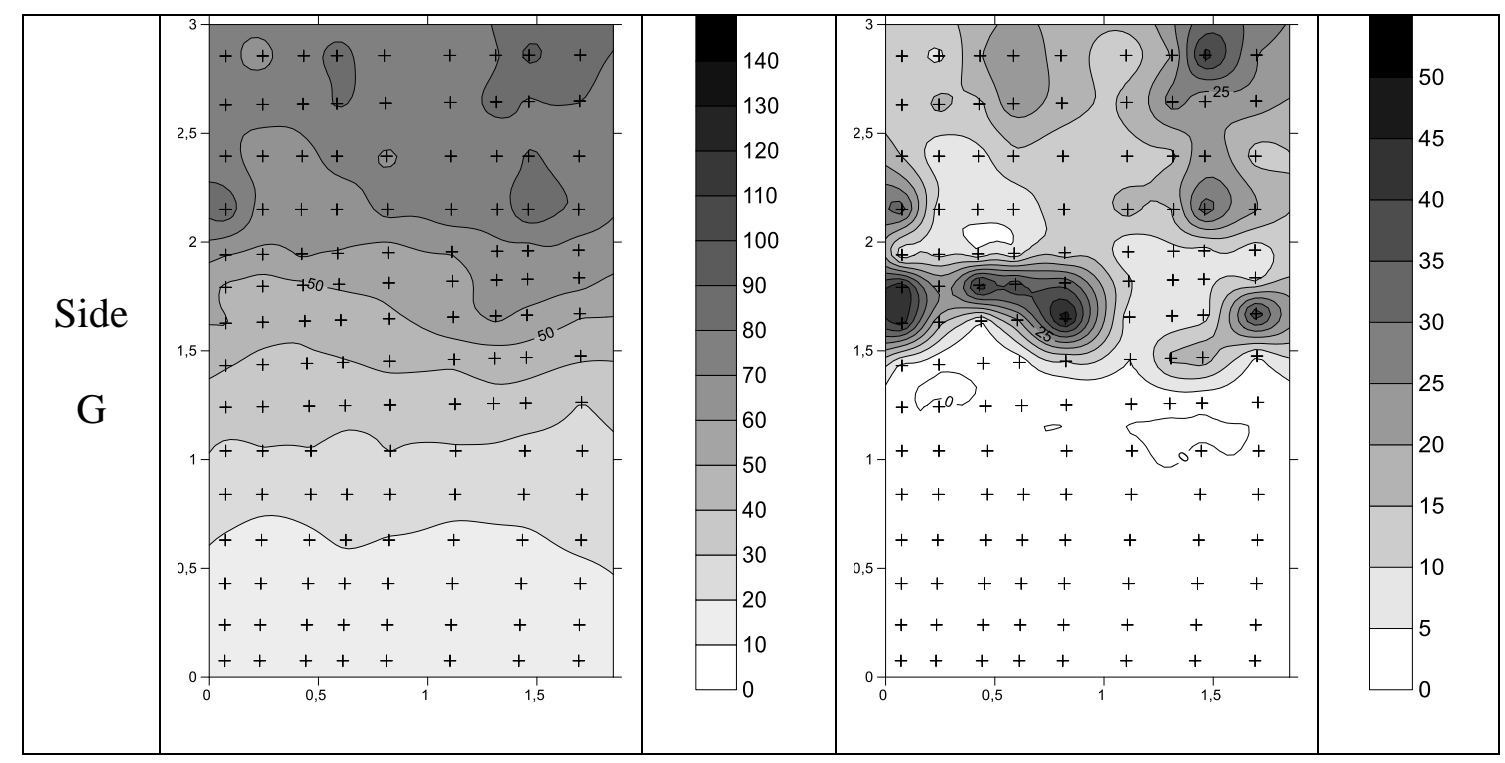

\section{Conclusions}

This paper aims to evaluate several sources of on-site error based on a dedicated campaign of concrete electrical resistivity measurements performed on a bridge in a marine environment. It was found that errors of assessment from the resistivity measurements are not negligible. The repeatability error increases linearly with the resistivity with a constant coefficient of variation of $13 \%$ and the local anisotropy of the material affects strongly the assessment for high resistivity values $(\rho \geq 80 \mathrm{k} \Omega . \mathrm{cm})$ : the coefficient of variation of total error reaches $30 \%$ for a $140 \mathrm{k} \Omega . \mathrm{cm}$ resistivity value.

The proposed modeling allows computing Probabilities of Wrong Assessment of probability of corrosion depending on different diagnosis thresholds. PWA's were illustrated and quantified based on the corrosion risk levels associated to the ranges of resistivity values as recommended by the RILEM.

That gives to the owner a mapping showing a rational quantification of the impact of measurement uncertainties on the diagnosis. Two options can follow: reduce the uncertainty by carrying out repeatability tests or use another techniques to reduce the 
doubt (half-cell potential measurements). The later can be assessed from probabilistic quality assessment of NDT (Sheils et al., 2012) and the method given in Schoefs et. al. (2012) for marine structures. Note that this pier was diagnosed passive on the basis of this whole information and visual inspection and that a single NDT tool cannot be as accurate as this complete diagnosis.

To widen the validity of these results, other uncertainties and errors resulting from formulation of concretes or contamination with carbonation, from distance (especially shorter) between Wenner electrodes and from other environments (temperature, humidity, rain) should be added.

\section{Acknowledgments}

The French project DéCoF-Ré (Décision Corrosion Fiabilité - Ré) is a cooperative research program between several partners: IFSTTAR, Université de Nantes \& Capacité SAS, Cerema (Ouest and Ile-de-France), SIXENSE Concrete and the Département de la Charente-Maritime.

The authors acknowledge the owner of the Ré Bridge, the Département de la CharenteMaritime (A. Audouin-Dubreuil) and the company SIXENSE Concrete (M. Brouxel) for their financial supports.

The authors are very grateful to R. Queguiner, S. Pasquiet, F. Landrin and J. Schneider from Cerema, W. Traverst and P. Boujard from IFSTTAR and M. Roche from Université de Nantes for performing the measurements and they also thank M. Barbier and his entire team (Département de la Charente-Maritime) for their help with the vessel. 


\section{References}

Andrade, C., \& Alonso, C. (2004). RILEM TC 154-EMC:Electrochemical Techniques for Measuring Metallic Corrosion - Recommendations - Test methods for on-site corrosion rate measurement of steel reinforcement in concrete by means of the polarization resistance method. Materials and Structures. 37, 623-643.

Azarsa, P. and Gupta, R. (2017). Electrical Resistivity of Concrete for Durability Evaluation: A Review. Advances in Materials Science and Engineering. Vol. 2017, ID 8453095, 30 pages. https://doi.org/10.1155/2017/8453095

Balayssac, J.P., Laurens, S, Arliguie, G., Breysse, D., Garnier, V., Dérobert, X., Piwakowskie, B. (2012). Description of the general outlines of the French project SENSO - Quality assessment and limits of different NDT methods. Construction and Building Materials. 35 (Oct 2012), 131-138.

Bastidas-Arteaga, E. \& Schoefs, F. (2015). Sustainable maintenance and repair of RC coastal structures. Proceedings Of The Institution Of Civil Engineers-Maritime Engineering. 168(4), 162173.

Boéro, J., Schoefs, F., Yañez-Godoy, H., \& Capra, B. (2012). Time-function reliability of harbour infrastructures from stochastic modelling of corrosion. European Journal of Environmental and Civil Engineering. 16(10), 1187-1201.

Bertolini, L., Elsener, B., Pedeferri, P., \& Polder, R. (2004). Corrosion of steel in concrete: prevention, diagnosis, repair. Weinheim: Wiley Vch Verlagsgesellschaft Mbh.

Bourreau, L., Bouteiller, V., Schoefs, F., Gaillet, L., Thauvin, B., Schneider, J. \& Naar, S. (2016). On-site corrosion monitoring - reliability. Materials, Systems and Structures in Civil Engineering 
Conference, Segment on Electrochemistry in Civil Engineering. Technical University of Denmark, Lyngby, Denmark.

Bentur, A., Diamond, S., \& Berke, N.S. (1997). Steel corrosion in concrete - Fundamentals and civil engineering practice. London, United Kingdom: E\&FN SPON.

Bourreau, L., Gaillet, L., Bouteiller, V., Schoefs, F., Thauvin, B., Schneider, J. \& Naar, S. (2018). Better understanding of tide's influence on half-cell potential measurements for reinforced concrete in marine environment. Proc. of 40th IABSE Symposium 'Tomorrow's Megastructures', 6 p., September 19-21 2018, Nantes, France.

Breysse, D., Yotte, S., Salta, M., Schoefs, F., \& Ricardo, J., Chaplain, M. (2009). Accounting for variability and uncertainties in NDT condition assessment of corroded RC-structures. European Journal of Environmental and Civil Engineering. 13(5), 573-591.

Breysse, D., Abraham, O. (Eds) (2005). Méthodologie d'évaluation non destructive de l'état d'altération des ouvrages en béton (in French). Presses de l'Ecole Nationale des Ponts et Chaussées.

Broomfield, J.P. (1997). Corrosion of steel in concrete - Understanding, investigation and repair. London: E\&FN SPN.

Cigna, R., Andrade, C., Nürnberger, U., Polder, R., Weydert, R., \& Seitz, E. (2003). COST 521 Corrosion of steel in reinforced concrete structures. Final Report: European Communities, Luxembourg, EUR 20599.

COST TU 1404. Towards the next generation of standards for service life of cement-based materials and structures. eBook of 1404 action of European Cooperation in Science and 
Technology 2015-2018, Ed. Schlicke, D., Azenha, M., Staquet, S., ISBN (e-book): 978-3-85125434-1, DOI: 10.3217/978-3-85125-434-1.

Cox, R.N., Cigna, R., Vennesland, O., \& Valente, T., (Eds). (1997). COST 509 - Corrosion and protection of metals in contact with concrete. Final Report: European Commission, Directorate General Science, Research and Development, Brussels, EUR 17608 EN.

Elsener, B. (2003). RILEM TC 154-EMC:Electrochemical Techniques for Measuring Metallic Corrosion - Recommendations - Half-cell potential measurements - Potential mapping on reinforced concrete structures. Materials and Structures. 36, 461-471.

Gowers, K.R., \& Millard S.G. (1999). Measurement of concrete resistivit for assessment of corrosion severity of steel using Wenner technique. ACI Materials Journal, 96(5), 536-541.

Hornbostel, K., Larsen, C.K., \& Geiker, M.R. (2013). Relationship between concrete resistivity and corrosion rate - A literature review. Cement and Concrete Composites. 39(0), 60-72.

Montemor, M.F., Simões, A.M.P., \& Ferreira, M.G.S. (2003). Chloride-induced corrosion on reinforcing steel: from the fundamentals to the monitoring techniques. Cement and Concrete Composites. 25(4-5), 491-502.

Nanukuttan, S.V., Basheer, P.A.M., Mc Carter, W.J., Tang, L., Holmes, N., \& Chrisp, T.M. (2015). The performance of concrete exposed to marine environments: Predictive modelling and use of laboratory/on site test methods. Construction and Building Materials. 93, 831-840.

Pasqualini, O., Schoefs, F., Chevreuil, M., \& Cazuguel, M. (2013). Measurements and statistical analysis of fillet welded joints geometrical parameters for probabilistic modelling of the fatigue capacity. Marine Structures. 34/dec. 2013, 226-248, doi: 10.1016/j.marstruc.2013.10.002. 
Polder, R. (2000). RILEM TC 154-EMC:Electrochemical Techniques for Measuring Metallic Corrosion - Recommendations - Test methods for on-site measurements of resistivity of concrete. Materials and Structures. 33, 603-611.

Polder, R. (2001). Test methods for on site measurement of resistivity of concrete -a RILEM TC154 technical recommendation. Construction and Building Materials. 15(2-3), 125-131.

Poupard, O., L'Hostis, V., Catinaud, S., \& Petre-Lazar, I. (2006). Corrosion damage diagnosis of a reinforced concrete beam after 40 years natural exposure in marine environment. Cement and Concrete Research. 36(3), 504-520.

Poupard, O., L'Hostis, V., Bouteiller, V., Capra, B., Catinaud, \& S., Francois, D. (2007). Corrosion diagnosis of reinforced concrete beams after 40 years exposure in marine environment by non destructive tools. Revue Européenne de Génie Civil.11(1-2), 35-54.

Raupach, M., Reichling, K., Broomfield, J., Gulikers, J., Schneck, U., \& Serdar, M. (2013). Inspection strategies for reinforcement corrosion surveys. Matérials and Corrosion. 64(2), 111115.

Reichling, K., Raupach, M., Broomfield, J., Gulikers, J., L'Hostis, V., \& Kessler, S. (2013). Full surface inspection methods regarding reinforcement corrosion of concrete structures. Materials and Corrosion. 64(2), 116-127.

Sanchez, J., Andrade, C., Torres, J., Rebolledo, N., Fullea, J. (2017). Determination of reinforced concrete durability with on-site resistivity measurements. Materials and Structures, 50(41).

Schoefs, F., Clément, A., \& Nouy, A. (2009). Assessment of ROC curves for inspection of random fields. Structural Safety. 31(5), 409-419. 
Schoefs, F., Boero, J., Clément, A., \& Capra B. (2012). The alpha delta method for modelling expert judgement and combination of non-destructive testing tools in risk-based inspection context: application to marine structures. Structure And Infrastructure Engineering. 8(6), 531-543.

Sheils, E., O'Connor, A., Schoefs, F. \& Breysse, D. (2012). Investigation of the effect of the quality of inspection techniques on the optimal inspection interval for structures. Structure And Infrastructure Engineering. 8(6), 557-568.

Tilly, G.P., \& Jacobs, J. (2007). CONREPNET - Concrete repairs - Performance in service and current practice. United Kingdom: IHS BRE Press.

Weydert, R. \& Gehlen, C. (1999). Electrolytic Resistivity of Cover Concrete: Relevance, Measurement and Interpretation. - Proceedings of the Eight International Conference ' Durability of Building Materials and Components', Vancouver, May 30 - June 3, 1999, (Lacasse, M.A.; Vanier, D.J. (Ed.)), NRC Research Press, Ottowa. 1, 409-419.

Wenner, F. (1915). A method of measuring earth resistivity. Bulletin of the Bureau of Standards. $12,469-478$

Woodward, R., Cullington, D.W., Daly, A.F., Vassie, P.R.W., Haardt, P., \& Kashner, R. (2001). Bridge management in Europe (BRIME)-Deliverable D14. Final Report. p. 228. 